\title{
Tailoring of the Microstructure of Laser Powder Bed Fused Inconel 718 Using Solution Annealing and Aging Treatments
}

\author{
Emilio Bassini *(D), Giulio Marchese (D) and Alberta Aversa (D) \\ Department of Applied Science and Technology, Politecnico di Torino, Corso Duca degli Abruzzi 24, \\ 10129 Torino, Italy; giulio.marchese@polito.it (G.M.); alberta.aversa@polito.it (A.A.) \\ * Correspondence: emilio.bassini@polito.it; Tel.: +39-0131229352
}

check for

updates

Citation: Bassini, E.; Marchese, G.; Aversa, A. Tailoring of the

Microstructure of Laser Powder Bed Fused Inconel 718 Using Solution Annealing and Aging Treatments. Metals 2021, 11, 921. https://doi.org/ $10.3390 /$ met11060921

Received: 18 May 2021

Accepted: 3 June 2021

Published: 5 June 2021

Publisher's Note: MDPI stays neutral with regard to jurisdictional claims in published maps and institutional affiliations.

Copyright: (c) 2021 by the authors. Licensee MDPI, Basel, Switzerland. This article is an open access article distributed under the terms and conditions of the Creative Commons Attribution (CC BY) license (https:// creativecommons.org/licenses/by/ $4.0 /)$.

\begin{abstract}
Inconel 718 (IN718) is a nickel-based superalloy with high weldability and is thus ideal for being processed via laser powder bed fusion (LPBF). Unlike traditional casting, LPBF IN718 develops a complex microstructure due to the rapid solidification that characterizes this manufacturing process. As a result, LPBF microstructures are different from those expected in equilibrium conditions, and for this reason, specific heat treatments should be designed. This paper, using differential scanning calorimetry (DSC), thermal mechanical analysis (TMA), and a field emission scanning electron microscope (FESEM), aims to develop a complete heat treatment that maximizes the material strength, thereby enhancing its microstructure. The paper shows that high-temperature annealing followed by two aging steps is the most suitable way to achieve the abovementioned task. More specifically, a complete dissolution of the $\delta$ phase via solution annealing at $1080^{\circ} \mathrm{C}$ is the key factor in gaining an even and intense precipitation of $\gamma^{\prime}$ and $\gamma^{\prime \prime}$ during the subsequent aging treatments. The microstructural analyses showed the elimination of needle-like $\delta$ particles and detrimental Laves phases. At the same time, intense precipitation of spherical and of discoidal reinforcing particles was achieved by performing the aging treatments at 720 and $630^{\circ} \mathrm{C}$, respectively.
\end{abstract}

Keywords: laser powder bed fusion; Inconel 718; microstructure; hardness; heat treatments

\section{Introduction}

Laser powder bed fusion (LPBF) is one of the most used additive manufacturing (AM) techniques for metallic components, especially those which are difficult or costly to process through conventional methods [1,2]. This production method becomes particularly interesting when complicated geometries are processed, especially if there are numerous wall thickness changes or hollow parts that characterize the part design [3].

The LPBF process is known for its peculiar way of forming the components. More precisely, they grow in a layer-by-layer fashion due to a laser beam that melts the powders only where necessary, based on a CAD drawing. This technique appears extremely appealing as it makes the near-net-shape production of customized metal parts with complex geometries possible [2,4-7].

However, the microstructures of LPBF-obtained materials are exceptionally different if compared with those derived from traditional manufacturing technologies (e.g., cast or wrought processes) [8,9]. Furthermore, the LPBF components are characterized by intense residual stresses inherited from fast cooling after the melting of the powders induced by the laser (cooling rates around $10^{6} \mathrm{C} / \mathrm{s}$ ) [8-12].

Porosity and lack of fusion defects may be detected in LPBF samples, mainly when materials with low weldability are processed. Nevertheless, IN 718, after a proper process parameter optimization, shows extremely high-density values as observed in the work of Calandri et al., who found that the porosity level achieved was always lower than $0.5 \%$ [13].

IN718 is one of the most studied Ni-based alloys for AM purposes. The main reason for this comes from its high-temperature strength coupled with extremely low strain-age 
cracking sensitivity and its low cracking susceptibility $[9,13]$. Additionally, this material possesses high creep and fatigue resistance even in harsh environments [14,15]. Consequently, IN718 can reliably be used in several fields. Most common applications fall within the aeronautical or the energy production fields, e.g., jet engines, chemical plants, or heat exchangers [16]. Because of its good weldability, a relative density close to $100 \%$ can be obtained by LPBF [13,17-19]. Moreover, this alloy presents mechanical properties comparable or even better than wrought or cast counterparts after receiving proper heat treatments $[9,18]$.

Most of the heat treatments applied to LPBF IN718 are derived from previously known recipes based on the conventionally processed alloy $[9,10,12,18,20,21]$, but the obtained results differ from expectations. Hence, the research started tailoring specific heat treatments for the AM version of this alloy. For instance, Li et al. [22] studied the microstructure and hardness evolution under different solution annealing temperatures, followed by standard aging treatments. As a result, Li et al. [23] developed a novel heat treatment (solutionizing at high temperature $1150{ }^{\circ} \mathrm{C}, 2 \mathrm{~h}$ ) followed by a single aging treatment at $700{ }^{\circ} \mathrm{C}$ for $12 \mathrm{~h}$, and this improved the ductility of the material with respect to the standard heat treatment (solution annealing plus double aging treatments).

IN718 contains $\mathrm{Nb}, \mathrm{Al}$, and $\mathrm{Ti}$, which in turn, combined with $\mathrm{Ni}$, forms two intermetallic phases with an excellent reinforcing effect, i.e., $\mathrm{Ni}_{3} \mathrm{Nb}\left(\gamma^{\prime \prime}\right)$ and $\mathrm{Ni}_{3}(\mathrm{Al}, \mathrm{Ti})\left(\gamma^{\prime}\right)$. The matrix is mainly reinforced with metastable $\gamma^{\prime \prime}$, which may transform into $\delta$ phase if exposed to a specific temperature range $\left(650-850^{\circ} \mathrm{C}\right)$ for a sufficient time [24-26]. This latter compound is not intended to strengthen the material, but if precipitated in the correct volume fraction at grain boundaries, it may improve creep resistance and reduce the grain growth at a high temperature [27].

The LPBF IN718 may present interdendritic segregation of $\mathrm{Nb}$ due to its low diffusivity. This feature is very likely to promote the formation of brittle Laves phases, i.e., (Ni, $\mathrm{Fe}, \mathrm{Cr})_{2}(\mathrm{Nb}, \mathrm{Mo}, \mathrm{Ti})$ [28]. These particles usually lead to a substantial deterioration of mechanical properties. Thus, they must be dissolved with a tailored solution annealing treatment [29].

This passage is crucial because the dissolution of undesired phases frees some additional $\mathrm{Nb}$, which is then used to form the $\gamma^{\prime}-\gamma^{\prime \prime}$ reinforcing system during the aging treatment.

A strong crystallographic texture, very fine dendrites, and a high fraction of Laves phases typically characterize the microstructure of as-built samples $[9,13,30]$. Naturally, the abovementioned microstructural characteristics are expected to significantly affect the material's mechanical properties, as discussed in other works [21,22]. For example, $\mathrm{Ni}$ et al. [31] discussed the effect of the in situ heat treatment of this alloy during the LPBF process. They stated that the material processed via LPBF showed a columnar grained microstructure with high dispersive precipitates ( $\gamma^{\prime \prime}$ phases at grains boundary, even-distributed $\gamma^{\prime}$ phases around the grains), which formed during the building process, leading to a general anisotropy in the mechanical properties. These facts were also confirmed by other researchers such as Calandri et al. [13].

From a generic perspective, tailored heat treatment should dissolve most of the segregations within the interdendritic regions, making the material as homogeneous as possible, settling the bases for enhancing the mechanical properties via aging treatments.

This work continues the extensive study regarding LPBF IN718 that was started by Calandri et al., who described the as-built microstructure of this material $[13,30]$. In our study, the optimization of a complete heat treatment for LPBF IN718 is described, with aims to increase its hardness, homogenize the microstructure, and avoid the precipitation of phases that may lower the material's mechanical properties (e.g., $\delta$ or TCP phases). This task is accomplished by coupling thermal analysis (DSC and TMA) with a microstructural assessment of the material via high-resolution SEM microscopy. More specifically, in this work, the effects of direct aging, solution annealing, and aging after annealing are 
considered together in order for us to design the microstructure and hardness of LPBF Inconel 718 alloy.

\section{Materials and Methods}

\subsection{Process Parameter and Powder Composition}

An EOSINT M270 dual-mode machine (EOS GmbH, Krailling, Germany) was used to process the Inconel 718 samples studied in this work. The equipment mentioned above uses a $200 \mathrm{~W}$ Yb fiber continuous laser to melt the powder bed locally. The printing process was performed operating with a bidirectional scanning strategy with a $67^{\circ}$ rotation between each adjacent layer. The samples were printed directly on a build platform without any support. The process parameters were already optimized in previous work [13]. More specifically, the laser power was set at $195 \mathrm{~W}$, the scan speed at $1200 \mathrm{~mm} / \mathrm{s}$, while the hatching distance, the spot size, and the layer thickness were 90, 100, and $20 \mu \mathrm{m}$, respectively. The samples were 24 cylinders of $15 \mathrm{~mm}$ diameter and $70 \mathrm{~mm}$ height, evenly distributed onto the building platform.

At the end of the productive cycle, the samples were removed from the build platform using electrical discharge machining (EDM). Commercial gas atomized Inconel 718 powders (EOS $\mathrm{GmbH}$ ) were used as feedstock, and their related chemical composition is provided in Table 1 . The powder size distribution and morphology were assessed in a previous paper, and thus here only $d_{10}, d_{50}$, and $d_{90}$ are reported, i.e., 18.7, 25.5, and $39.1 \mu \mathrm{m}$, respectively [13].

Table 1. Chemical composition in weight percent of the employed gas atomized powder.

\begin{tabular}{ccccccccccccc}
\hline $\mathbf{N i}$ & $\mathbf{C r}$ & $\mathbf{N b}$ & $\mathbf{M o}$ & $\mathbf{T i}$ & $\mathbf{A l}$ & $\mathbf{C o}$ & $\mathbf{C u}$ & $\mathbf{C}$ & $\mathbf{S i}+\mathbf{M n}$ & $\mathbf{P}+\mathbf{S}$ & $\mathbf{B}$ & $\mathbf{F e}$ \\
\hline 52.5 & 19 & 5.125 & 3.05 & 0.9 & 0.5 & $<1$ & $<0.3$ & $<0.08$ & $<0.35$ & $<0.015$ & $<0.006$ & Bal. \\
\hline
\end{tabular}

\subsection{Metallurgical State of the Inspected Samples}

In this paper, IN718 was studied in different metallurgical states. This experimental part was beneficial as it allowed us to understand better the precipitation and dissolution of the reinforcing the particles of this Ni superalloy. First of all, the material was studied in the as-built condition, then in the direct-aged one, i.e., aged right after the printing process. Next, the material was analyzed after solution annealing at two different temperatures, i.e., 980 and $1065{ }^{\circ} \mathrm{C}$, respectively. Next, the solution annealed samples were first and second aged. Then, the first aging optimization was performed using two different temperatures, i.e., 720 and $650{ }^{\circ} \mathrm{C}$. Lastly, the second aging effects were evaluated at 520 and $630{ }^{\circ} \mathrm{C}$, respectively. These temperatures were derived from previous studies from the same authors [13], where an initial DSC analysis was performed to identify the principal metallurgical transformation of the material. More specifically, every metallurgical condition was applied to 3 samples to verify the reproducibility of the treatments.

Table 2 provides a resuming list of all the assessed samples.

Table 2. List of the heat treatments performed $(X=1,2,4,8 \mathrm{~h} ; \mathrm{Y}=4,8 \mathrm{~h} ; \mathrm{Z}=1,2,4,8 \mathrm{~h})$.

\begin{tabular}{|c|c|c|c|}
\hline Sample Acronym & $\begin{array}{c}\text { Solution } \\
\text { Annealing }\end{array}$ & Aging & Second Aging \\
\hline DA650 & - & $650^{\circ} \mathrm{C}$ for $\mathrm{Y} h$ & - \\
\hline DA720 & - & $720^{\circ} \mathrm{C}$ for $\mathrm{Y} \mathrm{h}$ & - \\
\hline SA980 (X) A650 (Y) & $980^{\circ} \mathrm{C}$ for $\mathrm{X} h$ & $650^{\circ} \mathrm{C}$ for $\mathrm{Yh}$ & - \\
\hline SA980 (X) A720 (Y) & $980^{\circ} \mathrm{C}$ for $\mathrm{X} h$ & $720^{\circ} \mathrm{C}$ for $\mathrm{Yh}$ & - \\
\hline SA1065 (X) A650 (Y) & $1065^{\circ} \mathrm{C}$ for $\mathrm{X} h$ & $650^{\circ} \mathrm{C}$ for $\mathrm{Yh}$ & - \\
\hline SA1065 (X) A720 (Y) & $1065^{\circ} \mathrm{C}$ for $\mathrm{X} h$ & $720^{\circ} \mathrm{C}$ for $\mathrm{Y} \mathrm{h}$ & - \\
\hline SA1065 (X) A720 (Y) A520 (Z) & $1065^{\circ} \mathrm{C}$ for $\mathrm{X} h$ & $720^{\circ} \mathrm{C}$ for $\mathrm{Y} h$ & $520^{\circ} \mathrm{C}$ for $\mathrm{Z} \mathrm{h}$ \\
\hline SA1065 (X) A720 (Y) A630 (Z) & $1065{ }^{\circ} \mathrm{C}$ for $\mathrm{X} \mathrm{h}$ & $720^{\circ} \mathrm{C}$ for $\mathrm{Y} \mathrm{h}$ & $630^{\circ} \mathrm{C}$ for $\mathrm{Z} \mathrm{h}$ \\
\hline
\end{tabular}


The annealing treatments were performed in a low-pressure furnace TAV mini-jet 80 (TAV VACUUM FURNACES SPA Caravaggio, Bg, Italy). Quenching was achieved by modulating the nitrogen pressure within the furnace to $1.5 \mathrm{bar}$. On the other hand, all the additional heat treatments were performed in a traditional muffle furnace Nabertherm LH 60 (Nabertherm Gmbh, Lilienthal, Germany).

\subsection{Thermal Analysis with DSC and TMA}

Differential scanning calorimetry (DSC) was used to identify the critical temperature ranges where dissolution or precipitation of secondary phases occurs. More specifically, cylindrical samples with a diameter and height of 3.5 and $10 \mathrm{~mm}$, respectively, were put into alumina crucibles and heated up to $1200^{\circ} \mathrm{C}$ in a Setaram DSC/TGA 9216.18 (Caluireet-Cuire, France) with a heating rate ranging from 5 to $20^{\circ} \mathrm{C} / \mathrm{min}$. On the other hand, thermomechanical analyses (TMA) were performed using a SETSYS Evolution System between $400{ }^{\circ} \mathrm{C}$ and $1200^{\circ} \mathrm{C}$ in an argon atmosphere with a heating rate of 5 and $20^{\circ} \mathrm{C} / \mathrm{min}$. Samples were prepared using a precision metallographic cutting machine equipped with alumina disks. Abundant lubricant was used to avoid any material alteration due to overheating. The specimens for the DSC test were prepared along the building direction. Conversely, the TMA analysis was carried out by machining the samples with two different orientations, i.e., parallel and perpendicular to the building direction.

\subsection{Optical Assessment of the Samples}

The microstructural investigation was performed along the sample building direction in 3 different locations equally spaced, i.e., at 20,40 , and $60 \mathrm{~mm}$ from the building platform reference level. First, three disks with a $10 \mathrm{~mm}$ height were prepared using a metallographic cutting machine. This procedure was proper for assessing the microstructural homogeneity throughout the entire sample height. Then, the samples were prepared by grinding with $\mathrm{SiC}$ paper down to 2400 grit and polished with diamond suspensions $(6,3$, and $1 \mu \mathrm{m})$. The surface finishing was obtained with a prolonged polishing session using colloidal silica. Once the samples were mirror polished, they were etched using Kalling n.2 (waterless), i.e., a solution containing $100 \mathrm{~mL}$ ethanol, $100 \mathrm{~mL} \mathrm{HCl}$, and $5 \mathrm{gr}$ of $\mathrm{CuCl}_{2}$. The three sections described above were then investigated along the $\mathrm{XZ}$ section in 5 different positions equally spaced using a thermionic electron microscope Leo $1450 \mathrm{MP}$ by Zeiss (Oberkochen, Germany). The experimental campaign performed in these 15 regions evidenced a complete microstructural reproducibility and homogeneity. Based on this evidence, only the samples central sections were further investigated via advanced microscopy techniques using the field emission scanning electron microscope (FESEM) Merlin by Zeiss (Oberkochen, Germany), equipped with a Gemini column.

\subsection{Hardness Assessment of the Samples}

The average Brinell hardness of each sample slice was calculated by performing 5 indentations using an EMCO TEST M4U durometer (EMCO-TEST Prüfmaschinen GmbH, Kuchl, Austria) for a total of 15 indentations per sample. The test was performed by applying a $62.5 \mathrm{kgf}(\approx 613 \mathrm{~N})$ load for $15 \mathrm{~s}$.

\section{Results and Discussion}

\subsection{Thermal Analysis with DSC and TMA}

Figure 1 displays the signals recorded during the heating ramps performed on the asbuilt samples by setting different heating rates. Note that the peaks slightly shift to higher temperatures when increasing the heating rate and become more evident. The strongest peaks were used to identify the thermodynamic transformations, but their relative positions were assessed using the slowest ramp. 


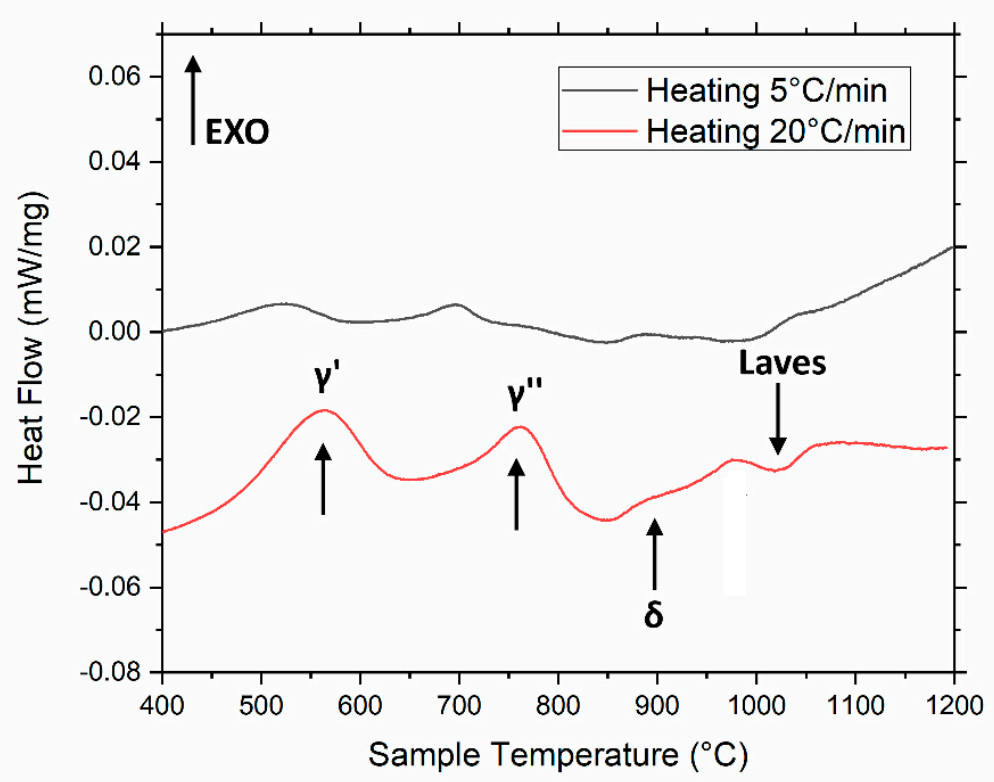

Figure 1. Differential scanning calorimetry (DSC) of as-built Inconel 718 at different heating rates. The arrows indicate the peaks detected, as also found in $[13,32]$.

As can be seen, three exothermic and an endothermic peaks can be observed in the heating ramp and are indicated with black arrows. Peaks are related to the precipitation of $\gamma^{\prime}, \gamma^{\prime \prime}$, and $\delta$ at 565,755 , and $880{ }^{\circ} \mathrm{C}$, respectively. These temperatures were also mentioned in a previous paper [13]. On the other hand, the endothermic peak found in the range $980-1070{ }^{\circ} \mathrm{C}$ indicates the dissolution of all the pre-existing metastable phases. The results of the TMA analysis are reported together with the collected DSC curves in Figure 2 using the same heating ramp. Note that each exothermal peak is associated with a contraction of the material, i.e., a downward inversion of the CTE. Conversely, the endothermal peaks are associated with expansions, i.e., upward inversions of the measured CTE. In the plot, samples obtained along $\mathrm{Z}$ (building direction) are referred to as Ver, while $\mathrm{XY}$ ones to as Hor.

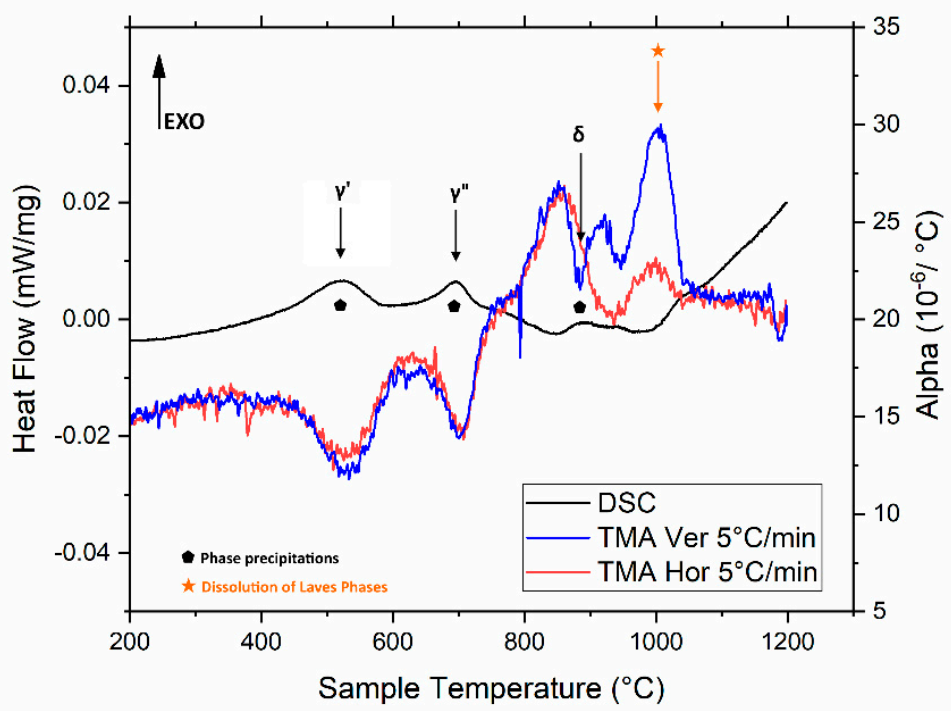

Figure 2. Thermomechanical analysis (TMA) of as-built IN718. Heating rate is $5^{\circ} \mathrm{C} / \mathrm{min}$. The relevant DSC curve is presented as well.

The detected exothermal peaks correspond to the precipitations of new phases. This phenomenon depleted the matrix of $\mathrm{Nb}$ from the solid solution, and therefore, the lattice 
distortion of $\gamma$ was reduced. This process led to a material contraction, as evidenced in the TMA signals. Conversely, the endothermal phenomena observed with the DSC analysis are related to the dissolution of the second phases. The resulting solid-state diffusion enriches the matrix in solute, causing the lattice expansion observed during the TMA.

The combined use of different thermal analyses reveals the following solid-state events in the as-built IN718, which can be interpreted based on the alloy CCT curves [33]: the precipitation of $\gamma^{\prime}$ between 450 and $630^{\circ} \mathrm{C}$; the precipitation of $\gamma^{\prime \prime}$ between 660 and $800{ }^{\circ} \mathrm{C}$; and the dissolution of metastable second phases (Laves) between 950 and $1050{ }^{\circ} \mathrm{C}$. A similar interpretation was also reported by Niang et al. [32] only for the exothermal peaks.

The TMA signals recorded on the vertical and horizontal samples (Figure 2) match everywhere except in the $850-950{ }^{\circ} \mathrm{C}$ temperature range (see Figure 2). This difference indicates that the lattice distortion caused by the dissolution of Laves phases and the formation of $\delta$ precipitates in this temperature range is not isotropic but occurs mainly along the building direction of the samples. This behavior may be connected to the elongated shape of the columnar grains inherited from the building process. This preferential orientation of the grain may act as a preferential nucleation site for the $\delta$ phase, which tends to grow in a single direction and may share numerous lattice positions with the austenitic matrix. Similar behavior was also observed in hot rolled austenitic stainless steels, where carbides preferentially develop at elongated grain boundaries of the rolled material, as discussed by Lakshmi et al. in a work about AISI 304 [34]. Furthermore, even though a TMA analysis was not performed, Fayed et al. noticed a higher amount of the $\delta$ phase along the building direction of LPBF IN718, in good agreement with the findings mentioned above [35].

The thermal analyses were also repeated with samples that underwent an annealing process. Figure 3 shows the results of the DSC and TMA performed on the solutioned samples at 980 and $1065{ }^{\circ} \mathrm{C}$ for $2 \mathrm{~h}$. These two temperatures were chosen based on a previous work by the same authors [13]. Again, the detected peaks are similar to those of the as-built material, with the peak that refers to the dissolution of pre-existing metastable phases being the only exception.

After solution annealing at $980{ }^{\circ} \mathrm{C}$, this peak is more evident because of the higher presence of $\delta$, which formed during the heat treatment [30]. Conversely, this peak is absent after solution annealing at $1065{ }^{\circ} \mathrm{C}$. This fact was due to the dissolution of all the pre-existing precipitates during the annealing.
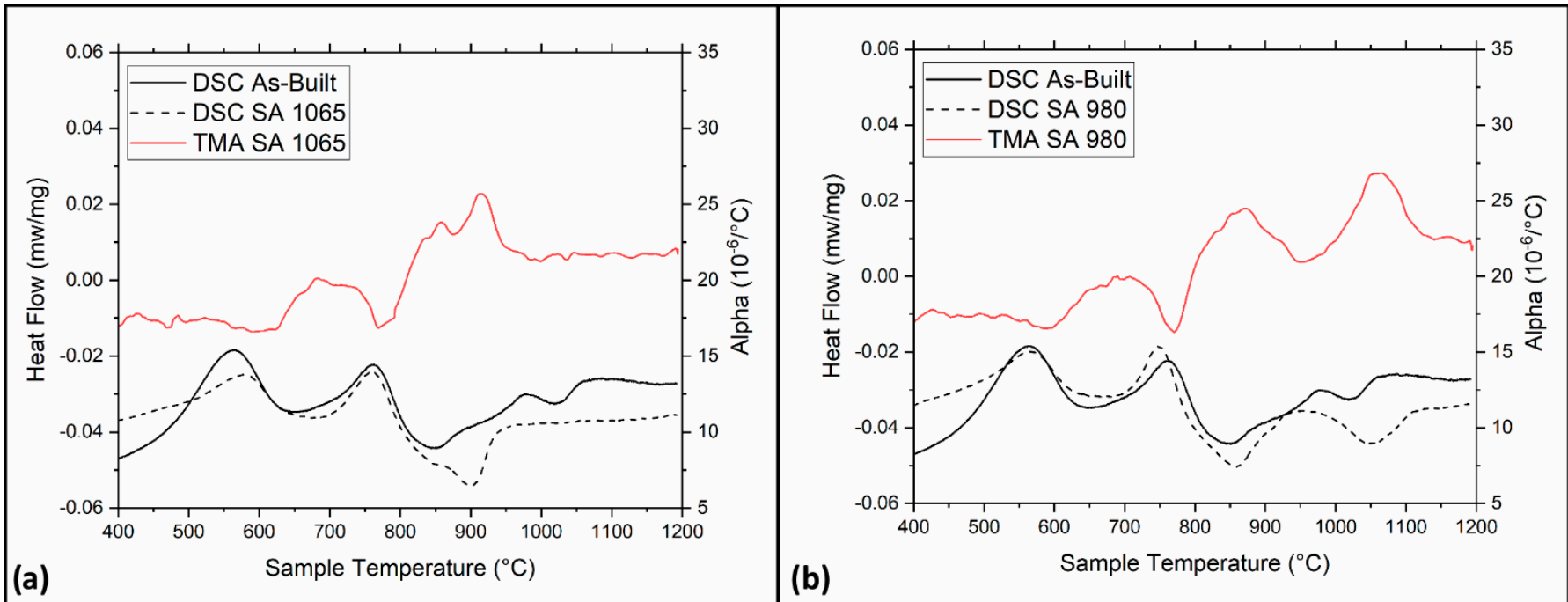

Figure 3. DSC and TMA of IN718 after solution annealing at $1065^{\circ} \mathrm{C}(\mathbf{a})$ and $980{ }^{\circ} \mathrm{C}(\mathbf{b})$; solid and dashed lines refer to DSC and TMA, respectively. 
The DSC and TMA analyses reported in Figures 2 and 3 are used to tailor the final heat treatment of the alloy because they provide a complete picture of the phase transformations brought by the thermal exposure

\subsection{Effects of the Heat Treatment on the Microstructure}

Figure 4 shows the microstructure of LPBF IN718 in the as-built state at low magnification using FESEM. Knowing the starting microstructure of the material makes it easier to understand the principal modification caused by each heat treatment phase. Despite the low magnifications, the columnar dendrites are easily visible, and many precipitates can be observed at their boundaries. This feature is compatible with a strong $\mathrm{Nb}$ segregation. It should be noted that the as-built microstructure was discussed in depth in a former work [13].

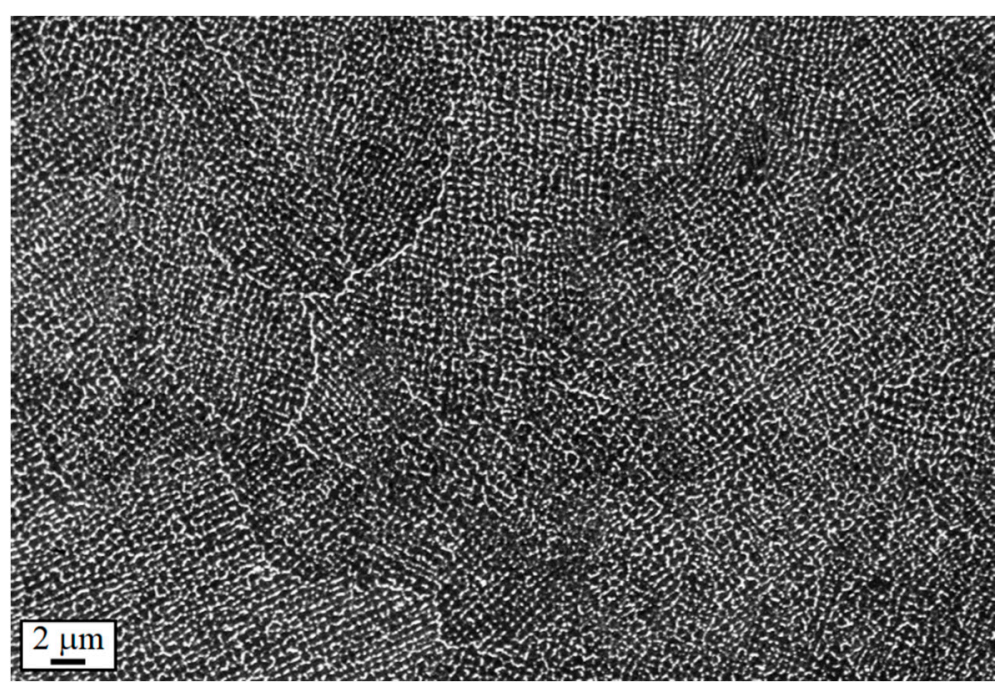

Figure 4. Microstructure of IN718 in the as-built state observed with secondary electron detector.

\subsubsection{Direct Aging at 650 and $720{ }^{\circ} \mathrm{C}$ for $8 \mathrm{~h}$}

Figure 5 shows the FESEM micrographs of the samples aged for $8 \mathrm{~h}$ at $650{ }^{\circ} \mathrm{C}$ and $720^{\circ} \mathrm{C}$ without a preliminary solution annealing. The direct aged samples are characterized by fine intergranular dendrites with a size of roughly $1 \mu \mathrm{m}$. At their boundaries, a large amount of segregation can be observed. These features were already present in the asbuilt state [13], as shown in Figures 4 and 5a, and they cannot be modified due to the low temperatures of the aging treatments. However, direct aging causes the precipitation of very small $\gamma^{\prime}$ particles uniformly dispersed, as shown in Figure 5b. In addition, $\gamma^{\prime \prime}$ precipitates were evidenced, mainly located along the interdendritic boundaries (Figure 5b). The most significant part of the $\gamma^{\prime \prime}$ phase formed at the dendritic boundaries because of the higher concentration of niobium in these regions [13]. Many small discoidal precipitates can be observed in samples aged at $720^{\circ} \mathrm{C}$, whereas some fine rounded particles were visible in the samples aged at $650{ }^{\circ} \mathrm{C}$. Based on the thermal analysis, one can conclude that the aging at $720{ }^{\circ} \mathrm{C}$ leads to large precipitations of the $\gamma^{\prime \prime}$ phase. Conversely, the aging at $650{ }^{\circ} \mathrm{C}$ leads only to precipitation of very fine $\gamma^{\prime}$ particles, which may cause a lower strengthening of the alloy.

Notably, together with rounded precipitates, a film of second phases was found in these samples at the interdendritic boundaries. This last evidence should be stressed because particles with this specific aspect ratio are generally detrimental for ductility since they act as a local stress raiser. 


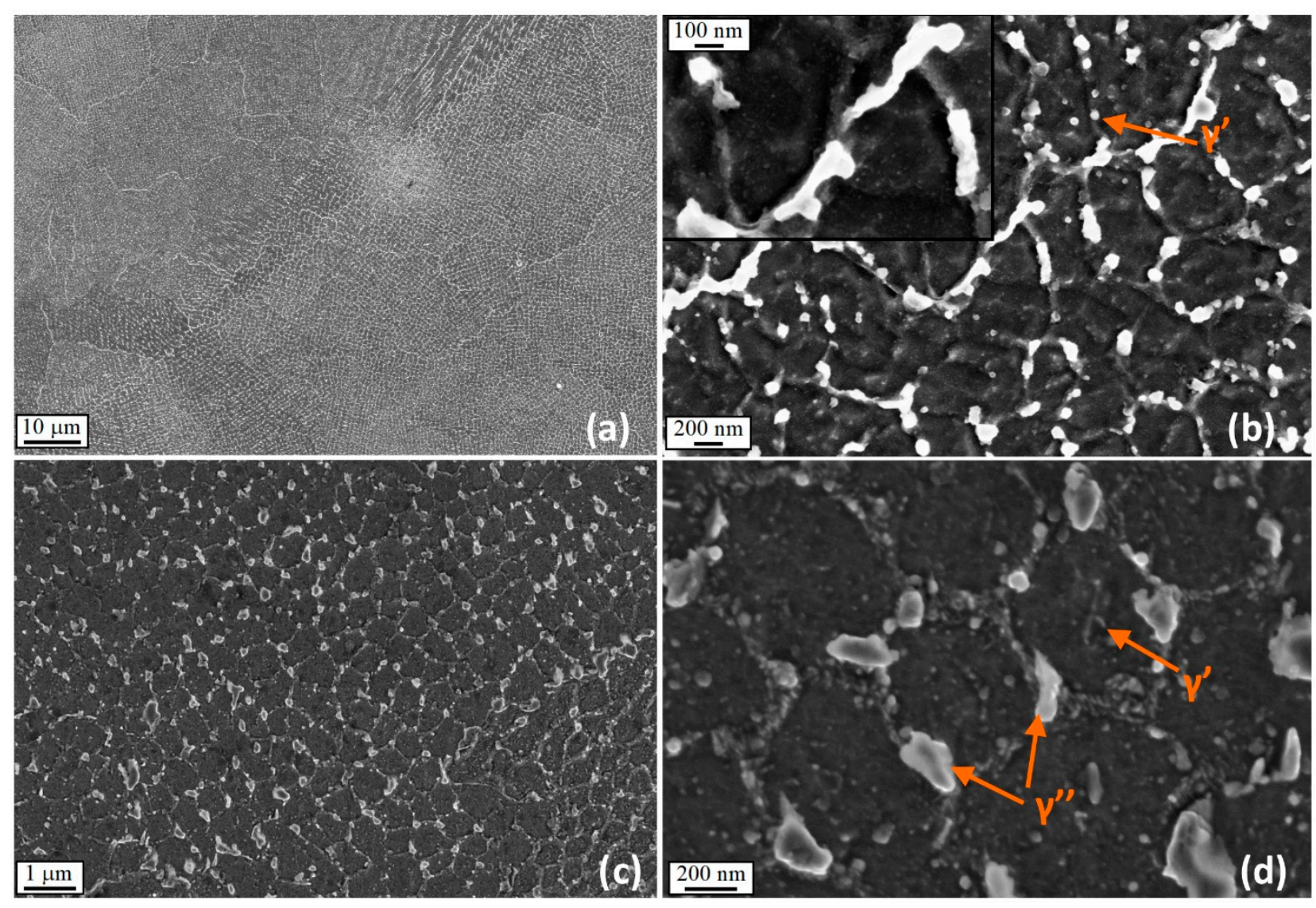

Figure 5. IN718 observed under a secondary electrons (SE) detector after direct aging at $650{ }^{\circ} \mathrm{C}$ for $8 \mathrm{~h}(\mathbf{a}, \mathbf{b})$ and after direct aging at $720^{\circ} \mathrm{C}$ for $8 \mathrm{~h}(\mathbf{c}, \mathbf{d})$.

\subsubsection{Solution Annealing}

To better understand the choices made in the following sections, it is crucial to understand which metallurgical alterations are expected after solution annealing. These modifications were extensively debated in [30], and the main points are discussed in the next subsection. LPBF IN718 requires a post-solution treatment to reduce the segregation of heavier elements (particularly $\mathrm{Nb}$ ) and to dissolve the interdendritic precipitates. Despite this, the annealing treatment can be performed only in a defined temperature range. When temperatures are excessively high, a strong grain coarsening leads to a sudden reduction of mechanical properties.

On the other hand, if the temperature is too low, an insufficient quantity of segregated particles will be dissolved, which limits the corrosion resistance of the alloy. According to this work, the best temperature range for enhancing the oxidation resistance falls between 980 and $1065^{\circ} \mathrm{C}$. The previous paper did not investigate the resulting microstructures or the mechanical properties after the annealing treatment, which are examined here instead.

Figure 6 shows the effect of the annealing treatment on the material hardness. When the treatment was performed at a low temperature, only negligible effects were obtained. The temperature was too low to dissolve any particles, and the hardness decreased only due to a reduction of the residual stresses. According to the work cited above, a time of $2 \mathrm{~h}$ was considered the best compromise to perform the subsequent heat treatment steps. 


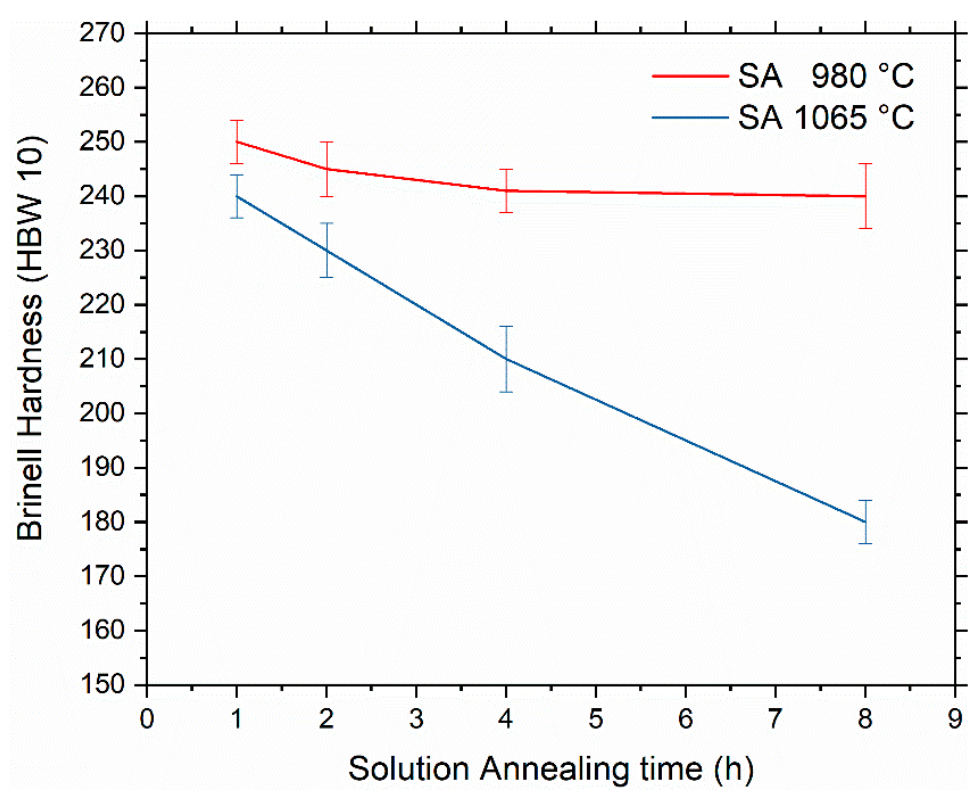

Figure 6. Brinell hardness as a function of solution annealing time at two different temperatures.

As observed, solution annealing led to a more consistent hardness decrease when performed at $1065^{\circ} \mathrm{C}$. Furthermore, this effect becomes highly evident when solution annealing lasts excessively (see Figure 6). This effect is mainly connected to excessive grain growth in the material. Therefore, the duration of the annealing step must be carefully chosen. Based on these considerations and previous experiences [30], the solution annealing was interrupted after $2 \mathrm{~h}$ to avoid excessive softening of the material.

\subsubsection{Solution Annealing at $980{ }^{\circ} \mathrm{C}$ and Aging at 650 or $720{ }^{\circ} \mathrm{C}$}

Figure $7 \mathrm{a}, \mathrm{b}$ shows the microstructure after solution annealing at $980{ }^{\circ} \mathrm{C}$ and aging at $650{ }^{\circ} \mathrm{C}$ at different magnifications. On the other hand, Figure $7 \mathrm{c}, \mathrm{d}$ shows the material solutioned at the same temperature but aged at $720^{\circ} \mathrm{C}$.

These conditions are characterized by relatively coarse plates of $\delta$ phase with a size ranging between 500 and $1000 \mathrm{~nm}$ in length. The $980^{\circ} \mathrm{C}$ solution annealing stabilized these needle-like precipitates. In fact, their dissolution may only happen between $1005^{\circ} \mathrm{C}$ and $1015^{\circ} \mathrm{C}$, as also mentioned in [27].

The presence of $\delta$ can affect the subsequent formation of the $\gamma^{\prime \prime}$ phase during the aging step because it reduces the availability of $\mathrm{Nb}$ in solid solution. Therefore, $\gamma^{\prime \prime}$ precipitation is not uniform. This experimental observation indicates that the annealing temperature is not high enough to dissolve the dendritic structures and to homogenize the material.

Nevertheless, the presence of brittle and elongated particles could be problematic for ductility and fatigue resistance. Thus, this microstructure cannot be considered ideal, and higher annealing temperatures should be investigated. 

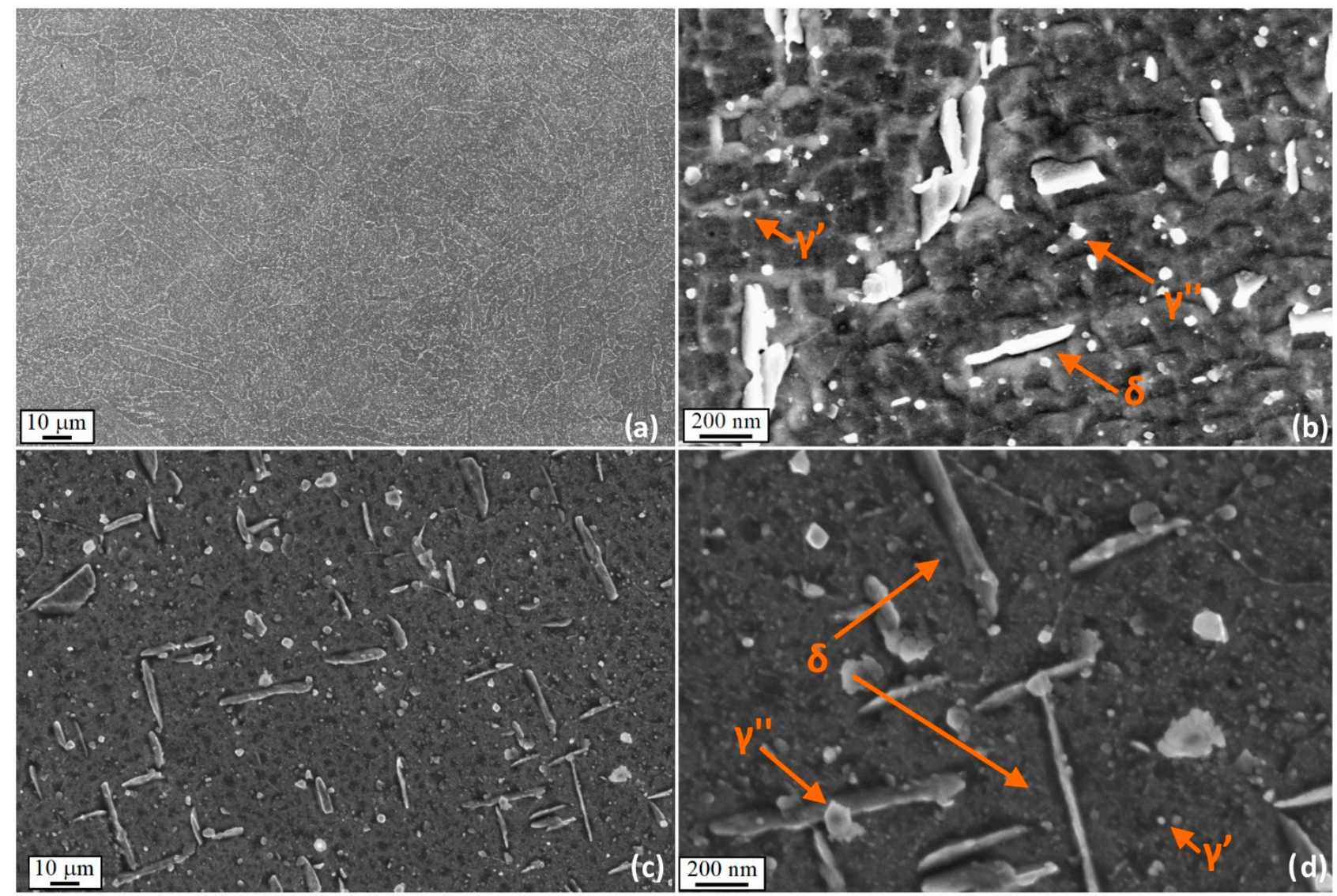

Figure 7. Microstructure after solution annealing at $980{ }^{\circ} \mathrm{C}$ for $2 \mathrm{~h}$ and subsequent aging at $650{ }^{\circ} \mathrm{C}$ for $8 \mathrm{~h}$ at different magnification low (a) and high (b). Microstructure after solution annealing at $980^{\circ} \mathrm{C}$ for $2 \mathrm{~h}$ and subsequent aging at $720{ }^{\circ} \mathrm{C}$ for $8 \mathrm{~h}$ at different magnification low (c) and high (d).

\subsubsection{Solution Annealing at $1065^{\circ} \mathrm{C}$ and Aging at 650 or $720^{\circ} \mathrm{C}$}

After solution annealing at $1065^{\circ} \mathrm{C}$, the grain boundaries became decorated with many intergranular precipitates. In contrast with the previous case, $\delta$ did not form during the heat treatment because it wholly dissolved during the annealing process see Figure 8 . This fact also explains why the dendritic subgranular structure was no longer visible after the heat treatment at $1065^{\circ} \mathrm{C}$. Furthermore, some very fine rounded particles were visible in the samples aged at $6500^{\circ} \mathrm{C}$, whereas many small discoidal precipitates can be observed in samples aged at $720^{\circ} \mathrm{C}$. Therefore, based on the thermal analysis, one can conclude that the aging at $720^{\circ} \mathrm{C}$ leads to a relevant increase of the hardness because of the large precipitations of the $\gamma^{\prime \prime}$ phase. Conversely, the aging at $650{ }^{\circ} \mathrm{C}$ leads to the precipitation of few and very fine $\gamma^{\prime}$ particles, and consequently a lower strengthening should be expected.

After this first optimization part, the main conclusion is that solution annealing is fundamental for gaining a sufficient degree of homogeneous precipitation. Conversely, in the direct aged samples, the precipitation of strengthening phases is highly irregular. Moreover, it occurs mainly at the interdendritic boundaries, where the local levels of $\mathrm{Nb}$, $\mathrm{Ti}$, and $\mathrm{Al}$ are higher due to microsegregation. 


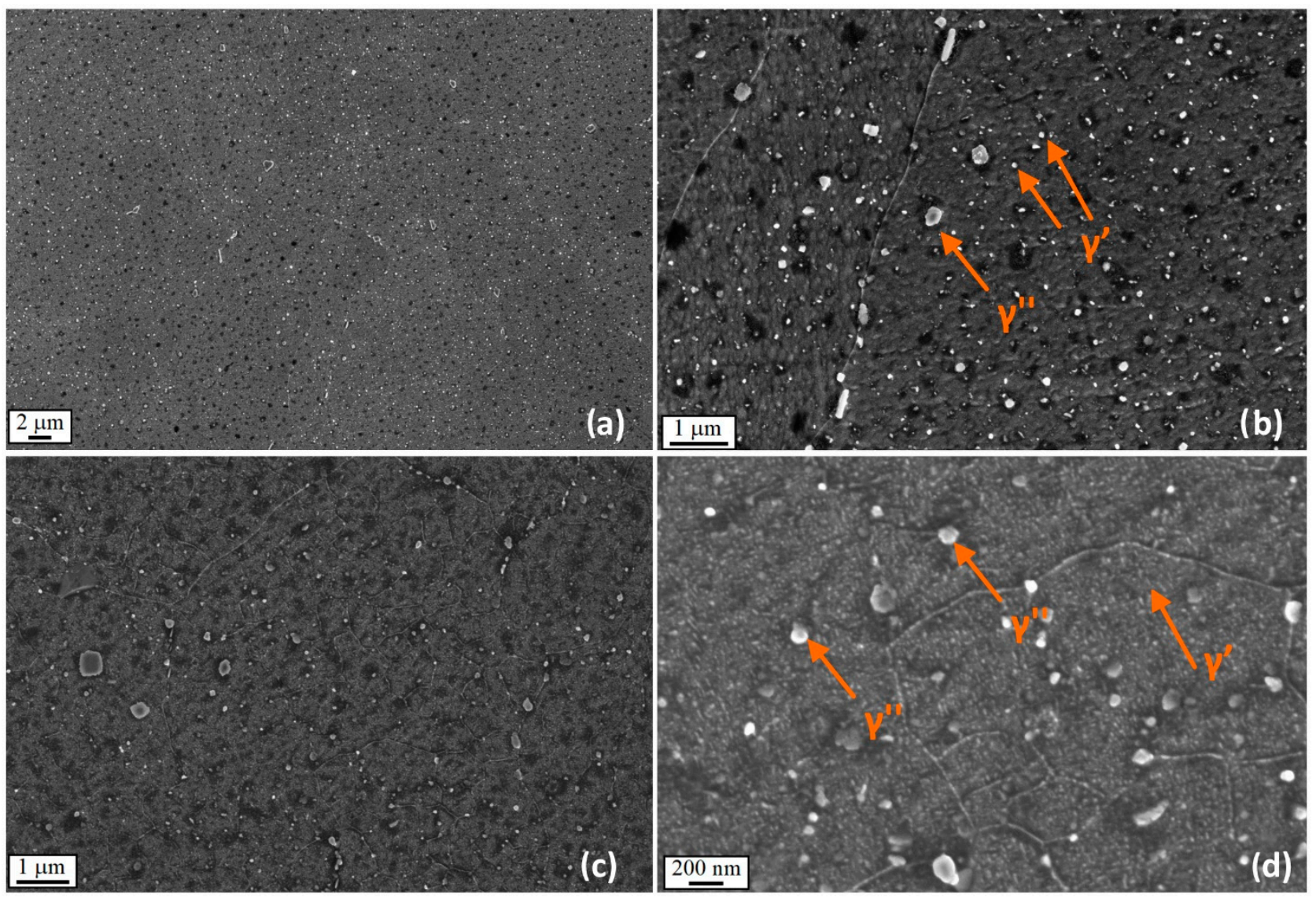

Figure 8. Microstructure after solution annealing at $1065^{\circ} \mathrm{C}$ for $2 \mathrm{~h}$ and subsequent aging at $650{ }^{\circ} \mathrm{C}$ for $8 \mathrm{~h}$ at low (a) and high (b) magnification. Microstructure after solution annealing at $1065^{\circ} \mathrm{C}$ for $2 \mathrm{~h}$ and subsequent aging at $720^{\circ} \mathrm{C}$ for $8 \mathrm{~h}$ at low (c) and high (d) magnification.

\subsection{Hardness after Direct Aging and Comparison with Solutioned and Aged Samples}

Figure 9 presents a comprehensive comparison of all the possible heat treatments analyzed up to now, considering that the hardness of the material in the as-built state was $264 \pm 6 \mathrm{HBW}$ 10. From this plot, it is possible to state some critical points: First of all, the direct aging at $720{ }^{\circ} \mathrm{C}$ is the treatment that provides the highest hardness. In comparison, the direct aging at $650{ }^{\circ} \mathrm{C}$ leads only to a subtle enhancement of the mechanical properties. Furthermore, the solution annealing at $980{ }^{\circ} \mathrm{C}$ leads only to a slight increase of hardness and is independent from the chosen aging temperature. Similar results were also obtained with solution annealing at $1065^{\circ} \mathrm{C}$ but only when the lower aging temperature was picked.

Although solution annealing at $1065^{\circ} \mathrm{C}$ by itself lowered the hardness considerably, this initial limitation was recovered entirely when the annealing was coupled with the aging at $720^{\circ} \mathrm{C}$. As shown in Figure 9 with a red triangle, the hardness level achieved is the second-highest value (irrespective of the aging time). Thus, even though the final hardness was slightly lower than the sample directly aged at $720^{\circ} \mathrm{C}$, the annealed and aged sample was preferred because of its more even microstructure. More specifically, this choice aims to dissolve the pre-existing eutectics precipitates, which allowed for a more homogeneous microstructure and a higher amount of free $\mathrm{Nb}$ for $\gamma^{\prime \prime}$ and $\gamma^{\prime}$ formation in the last steps of the treatment.

It is noteworthy that according to the microstructural observations, the solution step leads to a more uniform distribution of the strengthening $\gamma^{\prime \prime}$ precipitates after aging. Finally, the solution treatment is also considered an appropriate choice for getting rid of the undissolved Laves phases. 


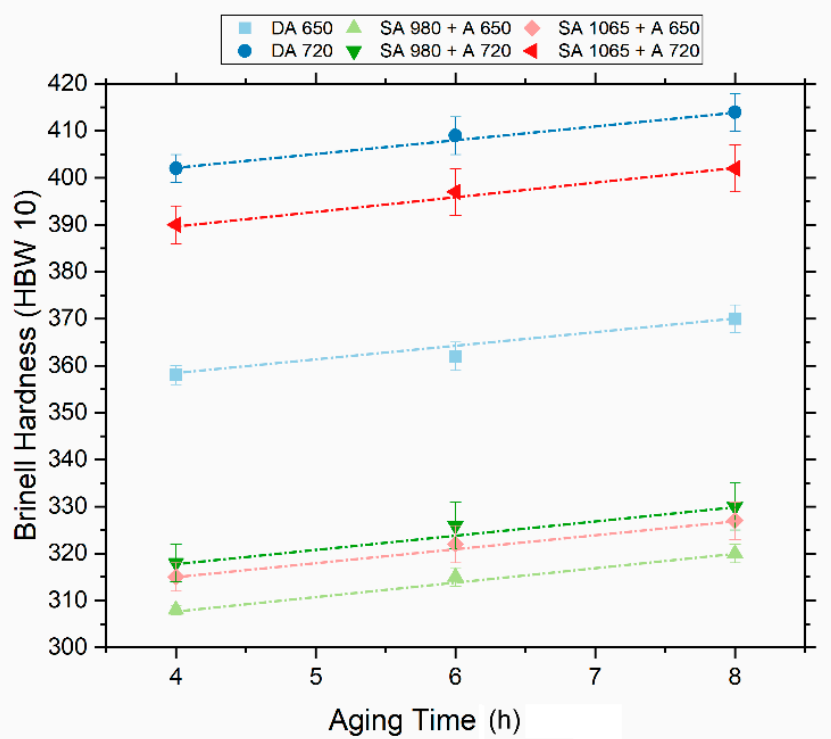

Figure 9. Hardness levels as an effect of all the heat treatment performed; dashed lines are the linear interpolations of the experimental points. All the linear regressions gave an $\mathrm{R}^{2}$ value higher than 0.993 .

The experimental observations performed led us to conclude that a preliminary solution annealing at $1065^{\circ} \mathrm{C}$ followed by first aging at $720{ }^{\circ} \mathrm{C}$ is the most suitable heat treatment recipe to enhance both hardness and microstructural uniformity. For this reason, from now on, the remaining part of the heat treatment optimization is performed on samples annealed at $1065^{\circ} \mathrm{C}$. Experimental points in Figure 9 are linearly interpolated, always obtaining $\mathrm{R}^{2}$ values higher than 0.993 , indicating an excellent fitting result.

\subsection{Second Aging at 520 and $630^{\circ} \mathrm{C}$}

Figure 10 shows the microstructure of the samples after the second aging step. The treatment was performed at two different temperatures. During the second aging, the amount of interdendritic precipitates further increased. Based on the thermal analysis outcome, $\gamma^{\prime}$ was expected to form at this temperature level. During the second aging, the new $\gamma^{\prime}$ particles synergically played with the $\gamma^{\prime \prime}$ developed during the first aging, generating a further increase in hardness. The peak hardness value was achieved quickly because of the rapid precipitation kinetic of $\gamma^{\prime}$. 


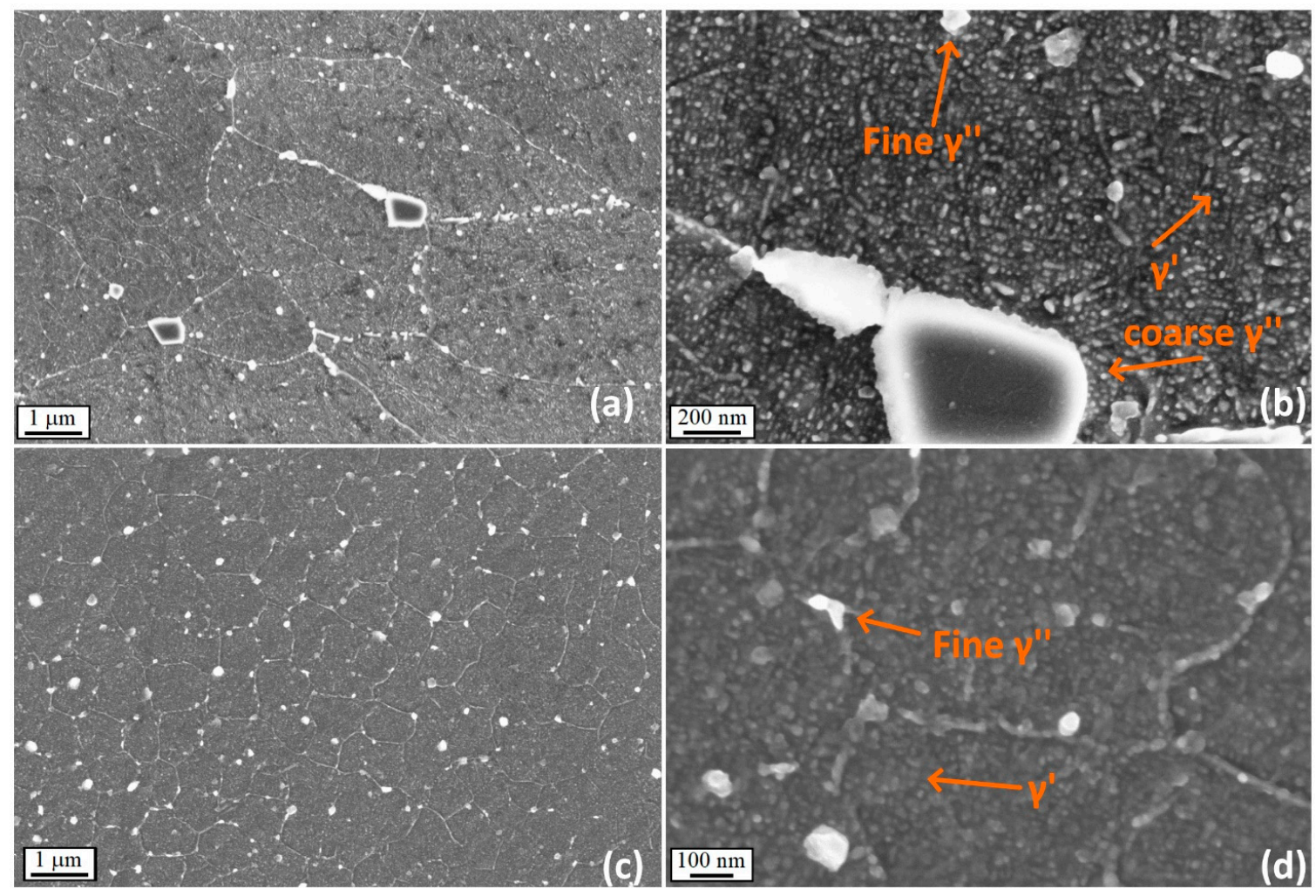

Figure 10. Microstructure after solution annealing at $1065{ }^{\circ} \mathrm{C}$ followed by the first aging at $720{ }^{\circ} \mathrm{C}$ and second aging at $520^{\circ} \mathrm{C}$ for $8 \mathrm{~h}$ at different magnification: low (a) and high (b). A second aging at $630^{\circ} \mathrm{C}$ for $8 \mathrm{~h}$ at different magnification: low (c) and high (d).

According to the micrographs at high magnification shown above, the exposure at more elevated temperatures promoted stronger precipitation, leading to a more effective reinforcement of the material, as discussed later in this section.

The Brinell hardness increased with the aging temperature, but the soaking time did not significantly contribute to it (Figure 11). For example, at $630^{\circ} \mathrm{C}$, the hardness reached a steady value after $4 \mathrm{~h}$ of treatment. Conversely, at $520^{\circ} \mathrm{C}$, a slight decrease of the hardness was observed after $8 \mathrm{~h}$ of aging. This effect could be due to the coarsening of the already formed precipitates without the contemporary formation of fresh reinforcing particles since the temperature is not high enough to promote the formation of further $\gamma^{\prime \prime}$.

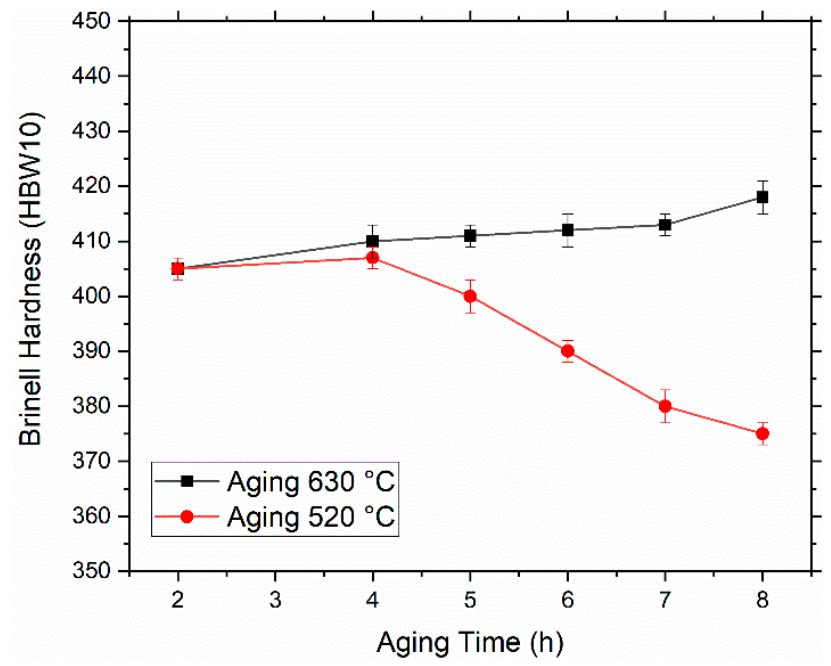

Figure 11. Hardness assessment after second aging at two different temperatures. 
The final hardness result achieved after the optimized heat treatment was $420 \mathrm{HBW}$ 10. This value was compared with others in the literature for traditional wrought alloy [36] and the LPBF [37].

For example, Kashaev et al. used traditional IN718 for mechanical characterization, with a $12 \mu \mathrm{m}$ grain size, and hardness was $210 \mathrm{HV}$ (ca. $210 \mathrm{HBW} 10$ according to conversion charts). Such a difference can be related to the significantly finer microstructure obtained in this work, which was preserved throughout the entire heat treatment by adequately limiting the soaking time during the annealing step. Similar conclusions can also be stated when comparing the results presented by Nikolaos et al. [38], where mechanical properties of welded IN718 were investigated. The finer microstructure obtained after TIG welding allowed us to obtain a final hardness of $240 \mathrm{HV}$ (ca. $228 \mathrm{HBW} 10$ according to conversion tables). In this case, the difference in hardness can be related to the different cooling rates during solidification, which is considerably slower in TIG applications. When hardness was compared with the material produced with the same laser bed techniques, it was found that the hardness gap was reduced. Jiang et al. [37] applied a traditional heat treatment to LPBF IN718, obtaining a final hardness of $404 \mathrm{HV}$ (ca. $381 \mathrm{HBW} 10$ according to conversion charts). This result is a further confirmation that careful optimization of the process parameters and heat treatment is vital to enhance the final mechanical properties of a component.

\section{Conclusions}

The DSC and TMA analyses provided a helpful starting point for studying the microstructural evolution of Inconel 718 after production through the LPBF process.

The samples solutioned at $980{ }^{\circ} \mathrm{C}$ showed plate-like $\delta$ precipitates. It was noticed that their volume fraction increases with the time of the solution treatment. The presence of the $\delta$ phase after solutioning at $980{ }^{\circ} \mathrm{C}$ was also confirmed by the DSC and TMA analyses.

The presence of $\delta$ affected the alloy's hardness in two opposite ways: it provided a certain strengthening during the solutioning treatment at $980^{\circ} \mathrm{C}$, preventing an excessive softening, and it strongly reduced the effectiveness of aging treatments since only a tiny amount of $\gamma^{\prime \prime}$ forms. Thus, the solution treatment at $1065^{\circ} \mathrm{C}$ for $2 \mathrm{~h}$ seems to be the best compromise between microstructural homogenization, the dissolution of the pre-existing second phases, and the possibility of avoiding grain coarsening.

The final hardness of the alloy was mainly controlled by the selection of the temperatures of the aging steps. The first aging temperature of $720{ }^{\circ} \mathrm{C}$ was found to be the best choice for the formation of strengthening $\gamma^{\prime \prime}$ particles. During the second aging step, further $\gamma^{\prime}$ strengthening particles can be formed. The most significant increase of hardness was obtained with the second aging performed at $630{ }^{\circ} \mathrm{C}$.

Author Contributions: Conceptualization, E.B. and G.M.; methodology, E.B. and G.M.; validation, E.B., G.M., and A.A.; formal analysis, E.B.; investigation, G.M.; data curation, E.B.; writing-original draft preparation, E.B.; writing-review and editing, A.A. and G.M.; supervision, E.B., G.M., and A.A. All authors have read and agreed to the published version of the manuscript.

Funding: This research received no external funding.

Data Availability Statement: All relevant data supporting this research work are presented within the paper.

Acknowledgments: The authors thanks Michele Calandri for his valuable work during the initial conceptualization of the paper.

Conflicts of Interest: The authors declare no conflict of interest.

\section{References}

1. Yap, C.Y.; Chua, C.K.; Dong, Z.L.; Liu, Z.H.; Zhang, D.Q.; Loh, L.E.; Sing, S.L. Review of selective laser melting: Materials and applications. Appl. Phys. Rev. 2015, 2, 041101. [CrossRef]

2. King, W.E.; Anderson, A.T.; Ferencz, R.M.; Hodge, N.E.; Kamath, C.; Khairallah, S.A.; Rubenchik, A.M. Laser powder bed fusion additive manufacturing of metals; physics, computational, and materials challenges. Appl. Phys. Rev. 2015, 2, 041304. [CrossRef] 
3. Ngo, T.D.; Kashani, A.; Imbalzano, G.; Nguyen, K.T.Q.; Hui, D. Additive manufacturing (3D printing): A review of materials, methods, applications and challenges. Compos. Part B Eng. 2018, 143, 172-196. [CrossRef]

4. Herzog, D.; Seyda, V.; Wycisk, E.; Emmelmann, C. Additive manufacturing of metals. Acta Mater. 2016, 117, 371-392. [CrossRef]

5. Sames, W.J.; List, F.A.; Pannala, S.; Dehoff, R.R.; Babu, S.S. The metallurgy and processing science of metal additive manufacturing. Int. Mater. Rev. 2016, 61, 315-360. [CrossRef]

6. Frazier, W.E. Metal additive manufacturing: A review. J. Mater. Eng. Perform. 2014, 23, 1917-1928. [CrossRef]

7. Gu, D.D.; Meiners, W.; Wissenbach, K.; Poprawe, R. Laser additive manufacturing of metallic components: Materials, processes and mechanisms. Int. Mater. Rev. 2012, 57, 133-164. [CrossRef]

8. Zhang, D.; Feng, Z.; Wang, C.; Wang, W.; Liu, Z.; Niu, W. Comparison of microstructures and mechanical properties of Inconel 718 alloy processed by selective laser melting and casting. Mater. Sci. Eng. A 2018, 724, 357-367. [CrossRef]

9. Chlebus, E.; Gruber, K.; Kuźnicka, B.; Kurzac, J.; Kurzynowski, T. Effect of heat treatment on the microstructure and mechanical properties of Inconel 718 processed by selective laser melting. Mater. Sci. Eng. A 2015, 639, 647-655. [CrossRef]

10. Zhang, D.; Niu, W.; Cao, X.; Liu, Z. Effect of standard heat treatment on the microstructure and mechanical properties of selective laser melting manufactured Inconel 718 superalloy. Mater. Sci. Eng. A 2015, 644, 32-40. [CrossRef]

11. Popovich, V.A.; Borisov, E.V.; Popovich, A.A.; Sufiiarov, V.S.; Masaylo, D.V.; Alzina, L. Impact of heat treatment on mechanical behaviour of Inconel 718 processed with tailored microstructure by selective laser melting. Mater. Des. 2017, 131, 12-22. [CrossRef]

12. Barros, R.; Silva, F.J.G.; Gouveia, R.M.; Saboori, A.; Marchese, G.; Biamino, S.; Salmi, A.; Atzeni, E. Laser Powder Bed Fusion of Inconel 718: Residual Stress Analysis Before and After Heat Treatment. Metals 2019, 9, 1290. [CrossRef]

13. Calandri, M.; Yin, S.; Aldwell, B.; Calignano, F.; Lupoi, R.; Ugues, D. Texture and microstructural features at different length scales in Inconel 718 produced by selective laser melting. Materials 2019, 12, 1293. [CrossRef]

14. Patel, A.D.; Murty, Y.V. Effect of cooling rate on microstructural development in alloy 718. Superalloys 2001, 718, 625-706.

15. Knorovsky, G.A.; Cieslak, M.J.; Headley, T.J.; Romig, A.D.; Hammetter, W.F. INCONEL 718: A solidification diagram. Metall. Trans. A 1989, 20, 2149-2158. [CrossRef]

16. Zaharia, S.M.; Chicos, L.A.; Lancea, C.; Pop, M.A. Effects of homogenization heat treatment on mechanical properties of inconel 718 sandwich structures manufactured by selective laser melting. Metals 2020, 10, 645. [CrossRef]

17. Carter, L.N.; Wang, X.; Read, N.; Khan, R.; Aristizabal, M.; Essa, K.; Attallah, M.M. Process optimisation of selective laser melting using energy density model for nickel based superalloys. Mater. Sci. Technol. 2016, 0836, 1-5. [CrossRef]

18. Wang, Z.; Guan, K.; Gao, M.; Li, X.; Chen, X.; Zeng, X. The microstructure and mechanical properties of deposited-IN718 by selective laser melting. J. Alloys Compd. 2012, 513, 518-523. [CrossRef]

19. Marchese, G.; Bassini, E.; Calandri, M.; Ambrosio, E.P.; Calignano, F.; Lorusso, M.; Manfredi, D.; Pavese, M.; Biamino, S.; Fino, P. Microstructural investigation of as-fabricated and heat-treated Inconel 625 and Inconel 718 fabricated by direct metal laser sintering: Contribution of Politecnico di Torino and Istituto Italiano di Tecnologia (IIT) di Torino. Met. Powder Rep. 2016, 71, 273-278. [CrossRef]

20. Zhou, L.; Mehta, A.; McWilliams, B.; Cho, K.; Sohn, Y. Microstructure, precipitates and mechanical properties of powder bed fused inconel 718 before and after heat treatment. J. Mater. Sci. Technol. 2019, 35, 1153-1164. [CrossRef]

21. Deng, D.; Peng, R.L.; Brodin, H.; Moverare, J. Microstructure and mechanical properties of Inconel 718 produced by selective laser melting: Sample orientation dependence and effects of post heat treatments. Mater. Sci. Eng. A 2018, 713, 294-306. [CrossRef]

22. Li, J.; Zhao, Z.; Bai, P.; Qu, H.; Liu, B.; Li, L.; Wu, L.; Guan, R.; Liu, H.; Guo, Z. Microstructural evolution and mechanical properties of IN718 alloy fabricated by selective laser melting following different heat treatments. J. Alloys Compd. 2019, 772, 861-870. [CrossRef]

23. Li, X.; Shi, J.J.; Cao, G.H.; Russell, A.M.; Zhou, Z.J.; Li, C.P.; Chen, G.F. Improved plasticity of Inconel 718 superalloy fabricated by selective laser melting through a novel heat treatment process. Mater. Des. 2019, 180. [CrossRef]

24. Azadian, S.; Wei, L.Y.; Warren, R. Delta phase precipitation in inconel 718. Mater. Charact. 2004, 53, 7-16. [CrossRef]

25. Jouiad, M.; Marin, E.; Devarapalli, R.S.; Cormier, J.; Ravaux, F.; Le Gall, C.; Franchet, J.M. Microstructure and mechanical properties evolutions of alloy 718 during isothermal and thermal cycling over-aging. Mater. Des. 2016, 102, 284-296. [CrossRef]

26. Cao, G.H.; Sun, T.Y.; Wang, C.H.; Li, X.; Liu, M.; Zhang, Z.X.; Hu, P.F.; Russell, A.M.; Schneider, R.; Gerthsen, D.; et al. Investigations of $\gamma^{\prime}, \gamma^{\prime \prime}$ and $\delta$ precipitates in heat-treated Inconel 718 alloy fabricated by selective laser melting. Mater. Charact. 2018, 136, 398-406. [CrossRef]

27. Páramo Kañetas, P.J.; Reyes Osorio, L.A.; Guerrero Mata, M.P.; De La Garza, M.; Páramo López, V. Influence of the Delta Phase in the Microstructure of the Inconel 718 subjected to "Delta-processing" Heat Treatment and Hot Deformed. Procedia Mater. Sci. 2015, 8, 1160-1165. [CrossRef]

28. Zhong, C.; Gasser, A.; Kittel, J.; Wissenbach, K.; Poprawe, R. Improvement of material performance of Inconel 718 formed by high deposition-rate laser metal deposition. Mater. Des. 2016, 98, 128-134. [CrossRef]

29. Tucho, W.M.; Cuvillier, P.; Sjolyst-Kverneland, A.; Hansen, V. Microstructure and hardness studies of Inconel 718 manufactured by selective laser melting before and after solution heat treatment. Mater. Sci. Eng. A 2017, 689, 220-232. [CrossRef]

30. Calandri, M.; Manfredi, D.; Calignano, F.; Ambrosio, E.P.; Biamino, S.; Lupoi, R.; Ugues, D. Solution Treatment Study of Inconel 718 Produced by SLM Additive Technique in View of the Oxidation Resistance. Adv. Eng. Mater. 2018, 20, 1-16. [CrossRef]

31. Ni, M.; Chen, C.; Wang, X.; Wang, P.; Li, R.; Zhang, X. Materials Science \& Engineering A Anisotropic tensile behavior of in situ precipitation strengthened Inconel 718 fabricated by additive manufacturing. Mater. Sci. Eng. A 2017, 701, 344-351. [CrossRef] 
32. Niang, A.; Viguier, B.; Lacaze, J. Some features of anisothermal solid-state transformations in alloy 718. Mater. Charact. 2010, 61, 525-534. [CrossRef]

33. Garcia, C.I.; Lis, A.K.; Loria, E.A.; DeArdo, A.J. Thermomechanical Processing and Continuous Cooling Transformation Bebavior of IN-718. In Proceedings of the Superalloys; Antolovich, S.D., Stusrud, R.W., MacKay, R.A., Anton, D.L., Khan, T., Kissinger, R.D., Klarstrom, D.L., Eds.; The Minerals, Metals \& Materials Society: Pittsburgh, PA, USA, 1992; pp. 527-536. [CrossRef]

34. Lakshmi, A.A.; Rao, C.S.; Buddi, T. Chapter five-Fractography analysis and constitutive modeling for dynamic plasticity of austenite stainless steel (ASS 304) at hot-working temperatures. In Woodhead Publishing Reviews: Mechanical Engineering Series, Modern Manufacturing Processes; Elsevier: Amsterdam, The Netherlands, 2020; ISBN 9780128194966.

35. Fayed, E.M.; Saadati, M.; Shahriari, D.; Brailovski, V. Effect of homogenization and solution treatments time on the elevatedTemperature mechanical behavior of Inconel 718 fabricated by laser powder bed fusion. Sci. Rep. 2021, 11, 1-17. [CrossRef] [PubMed]

36. Kashaev, N.; Horstmann, M.; Ventzke, V.; Riekehr, S.; Huber, N. Comparative study of mechanical properties using standard and micro-specimens of base materials Inconel 625, Inconel 718 and Ti-6Al-4V. J. Mater. Res. Technol. 2013, 2, 43-47. [CrossRef]

37. Jiang, R.; Mostafaei, A.; Pauza, J.; Kantzos, C.; Rollett, A.D. Materials Science \& Engineering A Varied heat treatments and properties of laser powder bed printed Inconel. Mater. Sci. Eng. A 2019, 755, 170-180. [CrossRef]

38. Alexopoulos, N.D.; Argyriou, N.; Stergiou, V.; Kourkoulis, S.K. Fatigue behavior of Inconel 718 TIG welds. J. Mater. Eng. Perform. 2014, 23, 2973-2983. [CrossRef] 